\title{
Inhibition of nocturnal acidity is important but not essential for duodenal ulcer healing
}

\author{
G Bianchi Porro, F Parente, O Sangaletti
}

\begin{abstract}
We have determined the relative importance of day and night time gastric acid inhibition for duodenal ulcer healing by comparing the antiulcer efficacy of a single morning with that of a single bedtime dose of ranitidine. One hundred and thirty patients with active duodenal ulcer were randomly assigned to a double-blind therapy with ranitidine $300 \mathrm{mg}$ at $8 \mathrm{am}$ or the same dose at $10 \mathrm{pm}$ for up to eight weeks. The antisecretory effects of these regimens were also assessed by $24 \mathrm{~h}$ intragastric $\mathrm{pH}$ monitoring in 18 of these patients. At four weeks ulcers had healed in $41 / 61(67 \%)$ of patients taking the morning dose and in $47 / 63(75 \%)$ of those receiving the nocturnal dose $(95 \%$ CI for the difference -0.09+0.25; p ns). At eight weeks, the corresponding healing rates were $82 \%$ and $85.5 \%$, respectively $(95 \% \mathrm{CI}$ for the difference $-0 \cdot 11+0 \cdot 17$; p ns). Both treatments were significantly superior to placebo in raising $24 \mathrm{~h}$ intragastric $\mathrm{pH}$, although the effects of the morning dose were of shorter duration than those of the nocturnal dose. These findings suggest that suppression of nocturnal acidity is important but not essential to promote healing of duodenal ulcers; a prolonged period of acid inhibition during the day (as obtained with a single large morning dose of $\mathrm{H}_{2}$-blockers) may be equally effective.
\end{abstract}

Several controlled clinical trials have recently shown that a large single nocturnal dose of $\mathrm{H}_{2-}$ blockers is highly effective in the short term treatment of duodenal ulcer giving healing rates comparable with those achieved with the same total daily dose administered twice daily. ${ }^{1-4}$ Because such a nightly dosage schedule almost completely suppresses nocturnal acid secretion but has little or no effect on day time intragastric acidity, ${ }^{56}$ it appears evident that the control of night time acidity may constitute the single most important factor in promoting the healing of duodenal ulcers. High ulcer healing rates, however, can also be obtained by therapeutic regimens to control diurnal intragastric acidity, such as divided doses of antacids..$^{7-9}$ In order to evaluate the relative importance of day and night time inhibition of gastric acid secretion on the duodenal ulcer healing process, we conducted a randomised double-blind trial to compare the efficacy of a large single morning dose of ranitidine with that of an equivalent single nocturnal dose in the short term treatment of duodenal ulcer. Furthermore, we compared the antisecretory effects of these two regimens in a subgroup of these patients by means of continuous $24 \mathrm{~h}$ intragastric $\mathrm{pH}$ monitor-

ing.

\section{Methods}

PATIENTS PART 1

One hundred and thirty patients with active duodenal ulcer ( $\geqslant 5 \mathrm{~mm}$ in diameter) endoscopically confirmed within the previous four days (except for patients participating in Part 2) were admitted to the study, which was approved by the hospital ethics committee.

Exclusion criteria included: age less than 18 years, concomitant gastric ulcer, upper gastrointestinal haemorrhage, recent peptic ulcer perforation, pyloric stenosis, Zollinger-Ellison syndrome, antiulcer medications (except antacids for symptomatic relief) during the preceding three weeks, pregnancy or lactation, and any serious medical condition capable of influencing the outcome of therapy.

All patients gave their informed verbal consent before admission to the study and were randomly allocated, according to a double blind protocol, either to ranitidine $300 \mathrm{mg}$ at $8 \mathrm{am}$ or ranitidine $300 \mathrm{mg}$ at $10 \mathrm{pm}$. Patients receiving ranitidine in the morning also took placebo at night, whereas those taking ranitidine at night received placebo in the morning. All tablets were identical in size and appearance and were dispensed in two coded bottles, marked 'morning' and 'night', each containing sufficient medication for 35 days' therapy. Patients were also provided with a known number of antacid tablets (Maalox) to be taken for the relief of pain. They were also instructed to record daily on a diary card pain episodes occurring during the day or night and the consequent antacid consumption. Treatment was for an initial period of four weeks; if the ulcer was endoscopically unhealed at the end of this first period, therapy was continued for a further four weeks and endoscopy performed again at eight weeks. Patients, however, were clinically reviewed every fortnight to assess drug compliance and the effectiveness of therapy.

At treatment randomisation, patients were asked about age, duration of dyspeptic symptoms and social habits. Basal acid output (BAO) and peak acid output (PAO), the latter after stimulation with pentagastrin $6 \mu \mathrm{g} / \mathrm{kg}$ subcutaneously (Peptavlon, ICI, Great Britain) were also determined before therapy in all patients, with the exception of those participating in Part 2 of the study. The $\chi^{2}$ test was used to assess the statistical significance of differences in healing rates of the two groups. $95 \%$ confidence intervals $(\mathrm{CI})$ for the differences in treatments were also evaluated. Other data were analysed by means of Student's $t$ test for unpaired samples.

PART 2

This part of the study was performed on 18
L Sacco Hospital, Milan

G Bianchi Porro,

O Sangaletti

Correspondence to: Professor G Bianchi Porro,

Gastrointestinal Unit, L Sacco Hospital, Via G B Gras
20157 Milano, Italy.

Accepted for publication

19 June 1989 
patients (14 men, four women), mean age $36 \cdot 7$ $(9 \cdot 2)$ (SD) with active duodenal ulcer subsequently admitted to the clinical trial. Each patient was studied on two separate occasions with a free interval of 48 hours. Patients were divided into two groups, each consisting of nine subjects; those in the first group were given one tablet of placebo or ranitidine $300 \mathrm{mg}$ at $8 \mathrm{am}$ while patients in the second group received one tablet of placebo or ranitidine $300 \mathrm{mg}$ at $10 \mathrm{pm}$ according to a randomised single blind scheme. In no case did more than seven days elapse between initial endoscopy and clinical trial entry.

Each patient underwent two $24 \mathrm{~h} \mathrm{pH}$-metries on an ambulant basis, but the time of starting $\mathrm{pH}$ monitoring was quite different for the two groups: patients receiving the morning dose were admitted to our laboratory before $8 \mathrm{am}$ after an overnight fast, whereas those taking the nocturnal dose were admitted before $5 \mathrm{pm}$ after fasting from $12 \mathrm{am}$.

After a pharyngeal anaesthesia with $2 \%$ xylocaine solution, a miniaturised bipolar glass electrode with a combined reference electrode (model $440 \mathrm{M} 4$, Ingold AG, Switzerland), connected to a portable recorder) Autronicord CM 18, Autronic, FRG), was passed through the nasopharynx into the stomach. The measuring tip was positioned, under fluoroscopic control in

TABLE I Characteristics of patients entering the trial. No significant differences were reported for any variable between the two groups

\begin{tabular}{|c|c|c|}
\hline & $\begin{array}{l}\text { Morming } \\
\text { dose } \\
(n=65)\end{array}$ & $\begin{array}{l}\text { Nocturnal } \\
\text { dose } \\
(n=65)\end{array}$ \\
\hline $\begin{array}{l}\text { Sex:male }(\mathrm{n}) \\
\text { Mean age }(\mathrm{yr})(\mathrm{SD}) \\
\text { Duration of dyspeptic symptoms } \\
\quad \text { (months) mean }(\mathrm{SD}) \\
\text { Smokers }(\%) \\
\text { Alcohol consumers }(\%)(>50 \mathrm{~g} / \mathrm{d}) \\
\text { PAO }(\text { mmol } \mathrm{H}+/ \mathrm{h}) \text { mean }(\mathrm{SD})\end{array}$ & $\begin{array}{l}46 \\
41 \cdot 1(11 \cdot 9) \\
94(68) \\
72 \% \\
28 \% \\
40 \cdot 4(10 \cdot 3) \\
\quad(n=56)\end{array}$ & $\begin{array}{l}49 \\
41 \cdot 8(12 \cdot 9) \\
100(65) \\
66 \% \\
25 \% \\
40 \cdot 7(11 \cdot 4) \\
(n=56)\end{array}$ \\
\hline
\end{tabular}

TABLE II Endoscopic evaluation of ulcer healing after four and eight weeks of treatment. In parentheses are reported the $95 \%$ confidence intervals for the differences

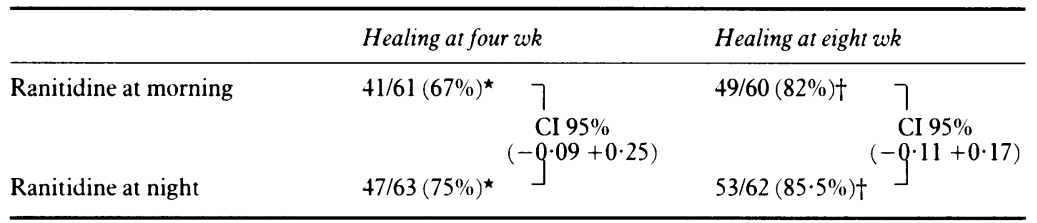

${ }^{\star} \mathrm{p}=0 \cdot 47 ; \mathrm{tp}=0 \cdot 74$. the gastric corpus, approximately $10 \mathrm{~cm}$ below the cardia. The recorder was calibrated at room temperature using commercial buffer solutions with a $\mathrm{pH}$ of $7 \cdot 00,4 \cdot 01$, and 1.09 (Radiometer, Copenhagen, Denmark) at the beginning of each test. Acidity was measured every five seconds for a total period of 24 hours.

The diet was normal and standardised for all subjects on each study day. Three meals were given (breakfast at $830 \mathrm{am}$, lunch at $1230 \mathrm{am}$ and dinner at $830 \mathrm{pm}$ ) for a total daily energy intake of approximately $2000 \mathrm{kcal}$. Wine was allowed at lunch and dinner, but the patients was invited to drink the same quantity during the two days. Water was freely allowed. Patients returned to the laboratory the next day and the electrode was removed exactly 24 hours after placing. Two separate $\mathrm{pH}$ profiles for placebo and ranitidine were constructed for each group of patients by calculating median $\mathrm{pH}$ values every 30 minutes. The area under the curve (AUC) of the $24 \mathrm{~h} \mathrm{pH}$ profiles for each test was calculated by the trapezoid rule, and statistical comparisons of the mean AUC values for placebo $v$ ranitidine were made using Student's $t$ test for paired data.

\section{Results}

PART 1

Of the 130 patients initially admitted to the study 65 received ranitidine $300 \mathrm{mg}$ in the morning and 65 ranitidine $300 \mathrm{mg}$ at night. The demographic characteristics of these patients are reported in Table I. One hundred and twenty four patients were evaluable for the determination of healing rates at four weeks and 122 for cumulative analysis of healing at eight weeks. Four patients on the morning regimen and two patients on the bedtime regimen defaulted at week 4; the reasons for withdrawal were: lost to follow up (three), lack of compliance (two), and late endoscopy (one). Two additional patients unhealed at week 4 , one on morning therapy and the other one on the nocturnal regimen, refused endoscopy at week 8 .

Endoscopic evaluation after four weeks of treatment showed that ulcer healed in $41 / 61$ patients $(67 \%)$ taking the morning dose and in $47 / 63(75 \%)$ of those receiving the nocturnal dose ( $95 \% \mathrm{CI}$ for the difference: $-0.09+0 \cdot 25 ; \mathrm{p} \mathrm{ns}$ ). After eight weeks the cumulative healing rates were $82 \%$ for the morning regimen and $85 \cdot 5 \%$

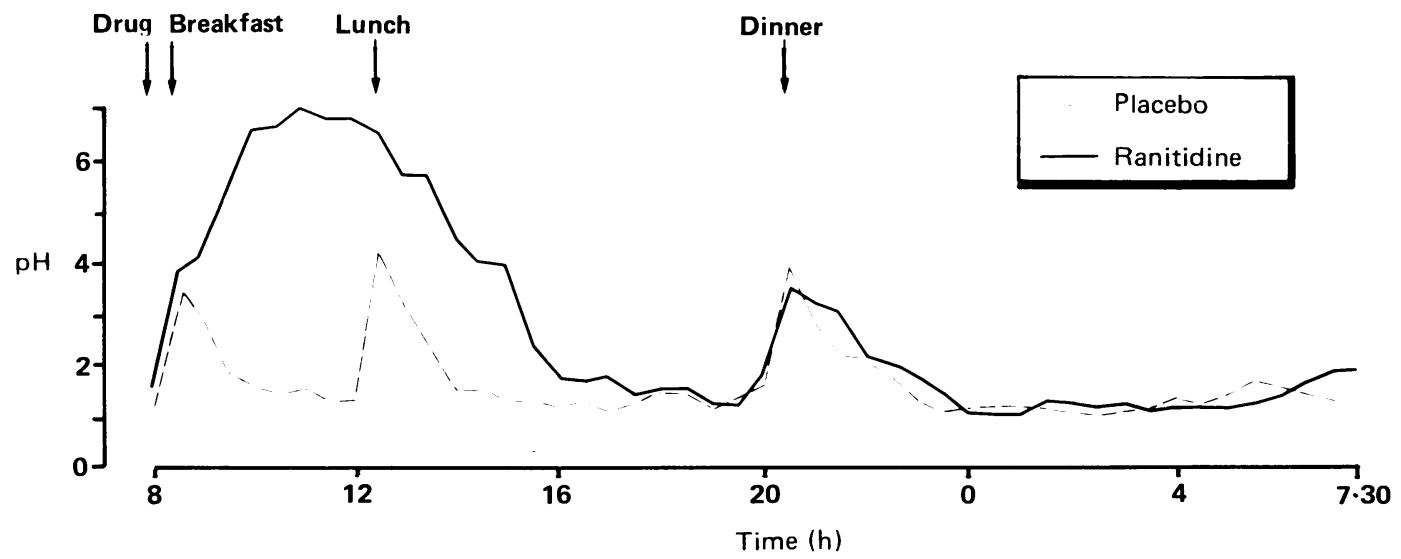




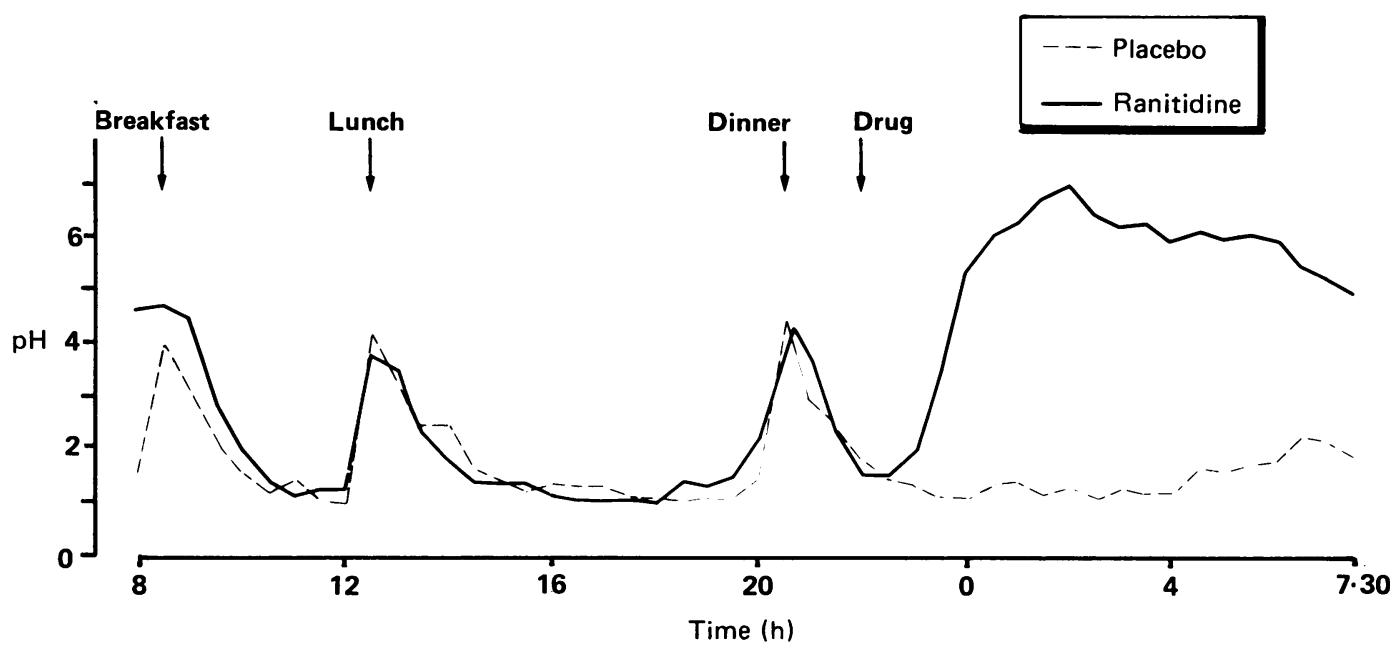

Figure 2: Median half hourly intragastric $p H$ in nine patients with duodenal ulcer receiving placebo or ranitidine $300 \mathrm{mg}$ at $10 \mathrm{pm}$.

for the nocturnal regimen $(95 \%$ CI for the difference $-0 \cdot 11+0 \cdot 17 ; \mathrm{p}$ ns, Table II). Similar proportions of patients in the two treatment groups were pain free by week 4 and no significant difference was observed between the two regimens regarding additional antacid consumption.

Among patients completing the trial, compliance was good and similar in both groups. The percentage of drug consumed during the treatment period was never less than $80 \%$. No clinically relevant side effects were observed with either regimen. No factor was shown to significantly affect healing of duodenal ulcers in the two treatment groups although cigarette smoking was associated with lower rates of healing at four weeks both with the morning and nocturnal regimen.

\section{PART 2}

The $24 \mathrm{~h} \mathrm{pH}$ profiles for placebo and ranitidine given at 8 am and for placebo and ranitidine given at $10 \mathrm{pm}$ are reported in Figures 1 and 2 .

It clearly emerges from Figure 1 that the ranitidine $\mathrm{pH}$ curve is markedly different from the placebo curve most of the daytime. Ranitidine in the morning takes effect at about $10 \mathrm{am}$, when $\mathrm{pH}$ concentrations rise above 5; high $\mathrm{pH}$ values are then maintained until $3 \mathrm{pm}$ after which $\mathrm{pH}$ returns to the basal values. During the remaining part of the day and the whole of the night the ranitidine curve resembles the placebo curve. As emerges from Figure 2, nocturnal ranitidine takes effect around midnight and $\mathrm{pH}$ values are maintained above 5 throughout the whole nocturnal period returning to basal values at about $10 \mathrm{am}$. During the remaining part of the day the $\mathrm{pH}$ profile for nocturnal ranitidine is essentially similar to that for placebo. Comparison between the two figures clearly reveals that the duration of action of nocturnal ranitidine on intragastric $\mathrm{pH}$ is longer than that of the morning regimen.

The 2-by-2 comparison between the mean AUC values of the $24 \mathrm{~h}$ pH profiles with the two regimens (Table III) shows that a significant difference exists between both placebo and ranitidine $300 \mathrm{mg}$ in the morning $(t=-5 \cdot 78$, $\mathrm{p}<0.001)$ and between placebo and ranitidine $300 \mathrm{mg}$ at night $(\mathrm{t}=-9 \cdot 24, \mathrm{p}<0 \cdot 001)$.
TABLE III Individual values and means $+S D$ of AUC of the 24 hour median $p H$ profiles calculated for placebo and ranitidine $(R) 300 \mathrm{mg}$ at $10 \mathrm{pm}$ (left side) and placebo and ranitidine $(R) 300 \mathrm{mg}$ at 8 am (right side)

\begin{tabular}{|c|c|c|c|c|}
\hline Patient & $P l$ & R at $10 \mathrm{pm}$ & $P l$ & $R$ at $8 a m$ \\
\hline $\begin{array}{l}1 \\
2 \\
3 \\
4 \\
5 \\
6 \\
7 \\
8 \\
9 \\
\text { Mean } \\
\text { (SD) }\end{array}$ & $\begin{array}{c}1.845 \\
1.613 \\
1.853 \\
2.907 \\
2.343 \\
1.821 \\
3.578 \\
2.284 \\
1.048 \\
2.254 \\
(0.628)\end{array}$ & $\begin{array}{l}5 \cdot 223 \\
3 \cdot 686 \\
5 \cdot 420 \\
5 \cdot 194 \\
4 \cdot 589 \\
5 \cdot 232 \\
5.977 \\
5 \cdot 361 \\
4 \cdot 424 \\
5 \cdot 011 \\
(0 \cdot 673)\end{array}$ & $\begin{array}{c}2 \cdot 674 \\
1 \cdot 778 \\
2 \cdot 986 \\
2 \cdot 534 \\
2 \cdot 017 \\
2.653 \\
2 \cdot 551 \\
2 \cdot 108 \\
1 \cdot 842 \\
2 \cdot 349 \\
(0.422)\end{array}$ & $\begin{array}{c}3.877 \\
3.521 \\
5.543 \\
3.649 \\
3.651 \\
5.654 \\
4.535 \\
4 \cdot 179 \\
3.284 \\
4 \cdot 210 \\
(0.868)\end{array}$ \\
\hline
\end{tabular}

\section{Discussion}

First, Dragstedt postulated that nocturnal acid secretion was the most important pathophysiological factor in duodenal ulcer and considered this the basis for its vagotomy operations. ${ }^{11}$ Subsequently, the importance of nocturnal acidity was confirmed by the high degree of efficacy of bedtime $\mathrm{H}_{2}$-blockers at low doses in preventing ulcer recurrence. ${ }^{2}$ In more recent years, several clinical studies have shown that the inhibition of nocturnal acid secretion alone, as obtained by large single bedtime doses of $\mathrm{H}_{2-}$ blockers, induces duodenal ulcer healing rates comparable with those achieved with regimens inhibiting gastric acidity throughout the whole $24 \mathrm{~h}$ period. ${ }^{1+}$ Successful healing of duodenal ulcers, however, has also been obtained using meal time doses of $\mathrm{H}_{2}$-blockers ${ }^{13}$ and divided doses of antacids, ${ }^{7-9}$ regimens designed mainly to inhibit daytime intragastric acidity. This indicates that the exact extent and duration of suppression of gastric acid secretion necessary to promote healing of duodenal ulcers is still uncertain.

In the first part of this study, we have shown that the antiulcer efficacy of ranitidine $300 \mathrm{mg}$ in the morning does not significantly differ from that of ranitidine $300 \mathrm{mg}$ at night. The healing rate observed with the morning regimen was only slightly inferior to the nocturnal healing rate at four weeks $(67 \% v 75 \%)$, but rates were practically identical at eight weeks $(82 \% v$ $85 \cdot 5 \%$ ). The $75 \%$ healing rate at four weeks in the group taking $300 \mathrm{mg}$ at night was comparable with the $73 \%$ rate obtained in a previous anti- 
ulcer trial with ranitidine nocte recently conducted in our unit; $;^{14}$ it is also on a par with the $78 \%$ rate observed by Lee $e t$ al in a large multicentre study comparing ranitidine $300 \mathrm{mg}$ at night with $150 \mathrm{mg}$ bid in a population of 424 patients. ${ }^{3}$ On the other hand, the good antiulcer efficacy of the morning dose shown in our study agrees with the preliminary results of a recent multicentre antiulcer study comparing single morning versus single nocturnal doses of famotidine. The authors found no significant differences between the healing rates obtained with the two regimens either at four or eight weeks of treatment. ${ }^{15}$ Our results, however, should still be considered preliminary ones, because of a difference of importance $(25 \%)$ in favour of the nocturnal regimen which cannot be excluded because of the relatively small size of the trial. Therefore, it would be worthwhile confirming these findings in a larger series and also checking for healing after two weeks of treatment to exclude a real difference between the two treatments in terms of rapidity of healing. In this regard Merki et al have recently shown that the antiulcer effects of ranitidine $300 \mathrm{mg}$ given at $6 \mathrm{pm}$ or at $10 \mathrm{pm}$ significantly differ at two weeks (healing rates of $74 \% v 50 \%$, respectively), but are comparable at four weeks. ${ }^{16}$ In the second part of the present work, we have shown that both ranitidine regimens are significantly effective in suppressing $24 \mathrm{~h}$ intragastric acidity as compared with placebo; however, the duration of the antisecretory action of the morning dose is shorter than that of the nocturnal dose, thus confirming the results observed by others with the twice daily dosage. ${ }^{617}$ The reason for the latter event is not very clear, but it may be seen as an 'escape phenomenon' of the gastric inhibitory effect of ranitidine induced by the meal taken at $1230 \mathrm{am}$. In support of this hypothesis, Johnston and Wormsley have recently reported that the nocturnal antisecretory effect of ranitidine at $6 \mathrm{pm}$ is virtually abolished by a meal taken later in the evening. ${ }^{18}$

As a large morning dose of ranitidine has virtually no effect on nocturnal intragastric acidity, its high antiulcer activity suggests that reducing daytime acid secretion may be as permissive as the suppression of night time acidity for the healing of duodenal ulcers. The pathophysiological significance of this observation is not yet known; a possible explanation is that diurnal acidity, particularly postprandial, plays a more important role in ulcerogenesis than was hitherto believed. Increased or prolonged acid secretory response to meals is, in fact, a well recognised physiological abnormality in a significant proportion of duodenal ulcer patients $;{ }^{1920}$ thus, a single large morning dose of $\mathrm{H}_{2}$-blockers, inhibiting the acid secretory response to breakfast and lunch, would result in high duodenal ulcer healing rates. In this regard, other authors have recently devoted their attention to the effect of food on the duodenal ulcer healing process showing that food induced gastric secretion may have a major negative effect, at least in ulcers which fail to respond to $\mathrm{H}_{2}$-blocker therapy. ${ }^{21}$

In conclusion, our findings suggest that the duodenal ulcer healing process may take place during the day as well as the night, provided that a sufficiently long period of gastric acid inhibition is assured. As a practical consequence, this means that it may not matter whether antisecretory drugs are administered at bedtime or during the morning if their dose is capable of reducing acid secretion for a long enough period.

The authors are grateful to Dr R P Walt of the University of Birmingham for his help and to Dr G Castelli of Glaxo Italia for supplying the drug used in this study.

1 Ireland A, Colin-Jones DG, Gear P. Ranitidine $150 \mathrm{mg}$ twice daily vs $300 \mathrm{mg}$ nightly in the treatment of duodenal ulcers. Lancet 1984; 2: 274-6.

2 Capurso L, Dal Monte PR, Mazzeo F, Menardo G, Morettin A, Saggioro A, Tafner G. Comparison of cimetidine $800 \mathrm{mg}$ once daily and cimetidine $400 \mathrm{mg}$ twice daily in acute duodenal ulceration. $\mathrm{Br}$ Med F 1984; 289: 1418

3 Lee FI, Reed PI,Crowe JP, McIsaac RL, Wood R. Acute treatment of duodenal ulcer: a multicentre study to compare ranitidine $150 \mathrm{mg}$ twice daily with ranitidine $300 \mathrm{mg}$ once at night. Gut 1986; 27: 1091-5.

4 Gitlin N, McCullough AJ, Smith JL, et al. A multicenter, double-blind, randomized, placebo-controlled comparison of nocturnal and twice-a-day famotidine in the treatment of active duodenal ulcer disease. Gastroenterology 1987; 92: 4853.

5 Deakin M, Glenny HP, Ramage JK, Mills JG, Burland WL, Williams JG. Large single daily dose of histamine $\mathbf{H}_{2}$ receptor antagonist for duodenal ulcer. How much and when? A clinical pharmacological study. Gut 1987; 28: 566 72 .

6 Celle G, Savarino V, Mela GS, et al. Once and twice daily dose of $\mathrm{H} 2$ antagonists revisited, using continuous intragastric $\mathrm{pH}$ monitoring. Scand f Gastroenterol 1988; 23: 385-90.

7 Peterson WL, Sturdevant RAL, Frankl HD, et al. Healing of duodenal ulcer with an antacid regimen. $N$ Engl f Med 1977 297: 341-5.

8 Ippoliti AF, Sturdevant RAL, Isenberg JI, et al. Cimetidine versus intensive antacid therapy for duodenal ulcer. A versus intensive antacid therapy for duodenal
multicenter trial. Gastroenterology 1978; 74: 393-5.

9 Fedeli G, Anti M, Rapaccini GL, De Vitis L, Butti A, Civello IM. A controlled study comparing cimetidine treatment to an intensive antacid regimen in the therapy of uncomplicated duodenal ulcer. Dig Dis Sci 1979; 24: 758-62.

10 Dragstedt LR. Vagotomy for gastro-duodenal ulcer. Ann Surg 1945; 122: 973-89.

11 Dragstedt LR. Peptic ulcer. An abnormality in gastric secretion. Am f Surg 1969; 117: 143-56.

12 Bianchi Porro G, Petrillo $M$. The natural history of peptic ulcer disease: The influence of $\mathrm{H} 2$-antagonist treatment. Scand $\mathcal{F}$ Gastroenterol 1986; 21 [suppl 121]: 46-52.

13 Lam SK, Lai CL, Fok KH, Hui WM. Duodenal ulcer healing by separate reduction of postprandial and nocturnal acid by separate reduction of postprandial and nocturnal acid
secretions have different pathophysiology. Gut 1985; 26: secretions

14 Parente F, Carrara $M$, Comin U, et al. Monodose serale di ranitidina nella terapia a breve termine dell'ulcera duodenale. Uno studio controllato in doppio cieco. Rec Progr Med 1985; 77: 154-7.

15 Dobrilla G, De Pretis G, Fontana G, et al. Famotidine (F) in single morning $(\mathrm{SM})$ vs single nocturnal $(\mathrm{SN})$ dose $(\mathrm{D})$ in the treatment of duodenal ulcer (DU) [Abstract]. Gut 1988; 29 : Al441.

16 Merki H, Witzel L, Huttemann W, et al. Early evening ranitidine administration promotes faster duodenal ulcer healing. Am 7 Gastroenterol 1988; 83: $362-4$.

17 Mills JG, Brunet PL, Griffiths R, et al. Oxmetidine: clinica pharmacological studies with a new $\mathrm{H} 2$-receptor antagonist. Gut 1982; 23: 157-63.

18 Johnston DA, Wormsley KG. The effect of food on ranitidineinduced inhibition of nocturnal gastric secretion. Aliment. induced inhibition of nocturnal

19 Malagelada J-R, Longstreth GF, Deering TB, Summerskill WHJ, Go V-LW. Gastric secretion and emptying after ordinary meals in duodenal ulcer. Gastroenterology 1977; 73 989-94.

20 Lam SK. Pathogenesis and pathophysiology of duodenal ulcer. Clin Gastroenterol 1984; 13: 447-71.

21 Johnston DA, Wormsley KG. Food is bad for ulcers [Abstract]. Gut 1987; 28: A1407. 